\title{
Diversity of Pest, Beneficial Arthropods and Other Non-Target Biota as Influenced by Degree of Pesticide Usage such as Indiscriminate, High, Moderate and Low Use Situations
}

\author{
B. Thirupam Reddy* and R.S. Giraddi
}

Department of Agricultural Entomology, College of Agriculture, Dharwad University of Agricultural Sciences, Dharwad - 580 005, Karnataka, India

*Corresponding author

\section{A B S T R A C T}

Keywords

Diversity, Simpson index (D), Pesticide usage patterns

Article Info

Accepted:

04 August 2019

Available Online:

10 September 2019
Diversity of insect pests influenced by pesticides usages, Simpson index (D) of biodiversity index of insects were calculated. Significant difference was observed among the different pesticide usage patterns, and respective unsprayed plots. In cabbage, $\mathrm{D}=0.62, \mathrm{D}=0.26$ in pesticide and unsprayed plots respectively and brinjal, $\mathrm{D}=0.64, \mathrm{D}=0.31$ (pooled) were recorded in pesticide and unsprayed plots respectively where is no significant difference of insect diversity was noticed in low pesticide usage crops maize $\mathrm{D}=0.83, \mathrm{D}=0.80$ in pesticide and unsprayed plots respectively and sorghum $\mathrm{D}=0.88, \mathrm{D}=0.86$ in pesticide and unsprayed plots respectively.

\section{Introduction}

Heavy reliance on synthetic fertilizers and pesticides (insecticides, fungicides, herbicides etc.) over the last 40 years or so globally and in India, has been a significant factor in the decline of invertebrate natural enemy populations in agricultural systems (Croft and Brown, 1975; Aebischer, 1991; Berry et al., 1996). Indiscriminate and high use of broad spectrum insecticides leads to development of resistance in insects and ill effects on the environment. Biodiversity conservation in the centre of origin is very important and any threat on this should be eliminated. Thus before recommending a chemical pesticide to be sprayed and quantity to be used in any crop, its impact on insect diversity should be studied in detail. In recent years, The Convention on Biological Diversity (CBD) has recognized predator-prey relationship as a key driver in the maintenance of biodiversity and ecosystem functioning.

Capital intensive chemical based production systems spread by the green revolution in India were not sustainable and lead to several environmental problems like replacement of crop varieties by hybrids, declined biodiversity and environmental resistance. Due to over and misuse of toxic chemicals in agriculture, ecocidal consequences viz., 
poisoning of birds, bees, fishes, insecticide resistance, resurgence, pesticide residues in food often described as "pesticide treadmill effects" have been documented (Altieri, 1995; Sivasubramanian and Wratten, 1995). To know the effect of pesticides on insect diversity in different crops were studied in this research.

\section{Materials and Methods}

Survey was conducted during Kharif and Rabi 2016-17 and 2017- 18 in selected crops in farmer's fields and at MARS Dharwad, to assess the effects of pesticide usage level on arthropod diversity. Following are the crops selected for study representing their pesticide usage levels, Indiscriminate (Brinjal and Cabbage), high (Pigeon pea and Chilli), moderate (Soybean and Chickpea) and low (Maize and Rabi sorghum) under situations of farmer's practices. Observations were taken on pest density and natural enemies on these selected crops. Standard methods of pest monitoring mentioned below were followed.

\section{Cabbage}

\section{Lepidopteran insects}

Twenty plants samples were randomly selected at 30, 45 and 60 DAT by using random row and plant co-ordinates to determine number of larvae per plant. While counting of larvae (DBM) it was ensured that the leaves were not violently disturbed since the larvae were very sensitive to disturbance and drop to ground even at slight jerk.

\section{Brinjal}

Incidence of shoot and fruit borer was recorded at weekly interval during vegetative stage. The withered or drooped shoots indicate initiation of shoot infestation. Total number of plants and number of infested shoots from each plot were observed for shoot infestation. Thereafter its incidence was noticed at each fruit picking on randomly selected ten plants. The number of healthy and damaged fruits on ten tagged plants was counted at each picking. The infestation was worked out by following the standard procedures as indicated below.

Number of drooping shoots

Per cent shoot infestation $=$ $\times 100$

Total number of shoots

Number of infested fruits

Per cent fruit infestation $=$ $\times 100$

Total number of fruits

\section{Redgram}

Observations on $H$. armigera were recorded on 3 randomly selected plants and expressed as larvae/plant. Leaf webbers were recorded per plant, while counts of pod fly maggots were recorded from 5 pods from randomly selected five plants.

\section{Chick pea}

During early hours of the day (7 to 9 am) observations for $H$. armigera larvae infesting the crop were taken along the metre-row length later the total numbers of pods, numbers of damaged pods per plant were counted for working out per cent damage.

Number of damaged pods Per cent pod infestation $=$------------ $\times 100$ Chilli

Total number healthy pods

\section{Thrips and mites}

Ten plants were brought to the laboratory (destructive sampling) and later observation on adults and immature of thrips and mites were counted from top 3 leaves under binacular. 


\section{Fruit borers}

Fruit borer complex viz; $H$. armigera (Hubner) and S. litura (Fabricius) larvae were recorded in the field. In each plot ten randomly selected plants were used to record the observations. Larvae of both $H$. armigera and $S$. litura, were counted and expressed as number of larvae per plant.

\section{Maize}

Stem borer: To know the extent of damage observations were recorded on dead hearts at 30, 45 and 60 days after emergence (DAE) on randomly selected plants.

\section{Soybean}

\section{Pod borer}

Observations on pod borer, Cydia ptychora incidence was recorded by uprooting 10 randomly selected plants in each treatment leaving border rows before harvesting. Number of pods per plant and number of pods damaged by the pod borer were recorded and per cent damage was worked out.

Number of damaged pods Per cent pod damage $=$----------------- $\times 100$

Total number of pods

\section{Rabi Sorghum}

Aphid: Nymphal and adult populations of aphids were recorded per $\mathrm{cm}^{2}$ area from 3 randomly selected tender leaves in 10 spots on each leaf. This was done on 10 plant samples per plot.

\section{Natural enemy observation}

Larvae of the pest were collected and individually placed in plastic containers $(4 \mathrm{~cm}$ diameter $\times 3 \mathrm{~cm}$ high) with tight fitting lids.
The larvae were reared on cabbage leaves in the laboratory. Emerged parasitoids were labelled, preserved in clear plastic tubes containing 90 per cent alcohol. Predators viz., coccinellids, spiders and lacewings were counted in situ and expressed in terms of population per plant in randomly selected plants.

\section{Results and Discussion}

The results of diversity of insect pests, beneficial arthropods and other non-target biota during kharif and rabi 2016-17 and 2017- 18 in selected crops depicting the pesticide usage situations as indiscriminate, high, moderate and low are presented as below. Cabbage and Brinjal were selected under indiscriminate pesticide usage as these crops receive highest pesticide interventions than recommendation. Cabbage with 15-17 sprays in crop period with pesticides such as Profenofos $50 \%$ EC, Methyl Parathion $50 \%$ EC and $2 \%$ EC, Carbofuran $3 \%$ G, Indoxacarb14.5\% SL, Cypermethrin $25 \%$ EC and $10 \%$ EC, Fipronil $5 \%$ SL, Imidacloprid $17.8 \%$ SL and Spinosad 2.5 \% SC. Similarly brinjal crop also recieves indiscriminate pesticide usasge with 16-18 sprays with pesticides such as Profenofos $50 \%$ EC, Methyl Parathion 50\%EC and $2 \%$ EC, Monocrotophos $36 \%$ SL, Quinolphos $25 \%$ EC, Carbofuran $3 \%$ G, Carbosulfan $25 \%$ EC, Fenvalerate $20 \% \mathrm{EC}$ and Cypermethrin $25 \%$ EC.

Under the category of high pesticide usage, Chilli and redgram were selected. Chilli with 12-13 sprays (Profenofos $50 \%$ EC, Methyl Parathion 50\%EC and $2 \%$ EC, Monocrotophos $36 \%$ SL, Acephate $75 \%$ SP, Carbofuran $3 \%$ G, Cypermethrin $25 \%$ EC and $10 \%$ EC, Fipronil $5 \%$ SL, Imidacloprid $17.8 \%$ SL) and Redgram with 5-7 sprays (Profenofos $50 \%$ EC, Lambda cyhalothrin $5 \%$ EC, Quinolphos $25 \%$ EC, Imidacloprid 
$17.8 \%$ SL, Acephate $75 \quad \% \quad$ SP and Dichlorovos $76 \%$ EC) under farmers field situations.

Soybean and chickpea were selected as moderate pesticide usage crops, with 4-5 and 2-3 spays respectively. Maize and rabi sorghum were selected as low pesticide usage crops with 1-2 sprays only used.

To know the diversity of insect pests influenced by pesticides usages, Simpson index (D) of biodiversity index of insects were calculated. Significant difference was observed among the different pesticide usage patterns, and respective unsprayed plots. In cabbage, $\mathrm{D}=0.62, \mathrm{D}=0.26$ in pesticide and unsprayed plots respectively and brinjal, $\mathrm{D}=0.64, \mathrm{D}=0.31$ (pooled) were recorded in pesticide and unsprayed plots respectively where is no significant difference of insect diversity was noticed in low pesticide usage crops maize $\mathrm{D}=0.83, \mathrm{D}=0.80$ in pesticide and unsprayed plots respectively and sorghum $\mathrm{D}=0.88, \mathrm{D}=0.86$ in pesticide and unsprayed plots respectively (Table 1).

Table.1 Diversity of insect pests influenced by pesticides spray as indicated by

Simpson's index (D)



The present investigation showed that low pesticide usage patterns did not have any adverse effect on the natural enemy diversity, which was measured by using indices of species richness, diversity and evenness. The order of Simpson's index for different pesticide use situations in crops designated was of low pesticide $>$ moderate $>$ high $>$ indiscriminate usage, indicating profound influence of pesticide usage on insect communities. Similar findings were noticed with the work of Dey, 2016 who concluded that, indiscriminate use of insecticide should be avoided but the application of insecticide 
should be fitted on need based application in IPM Programme. The insecticide use for the management of insects should be needed at low doses, creating no pollution problem yet effective to the insect and be well fitted in management tactics without any hazards to parasitoids, predatory insects, entomophilic pathogens and pollinators. Firas, 2014 also reported that, extensive use of pesticides in agriculture can affect natural enemies, birds and wildlife $(70.19 \%)$, contaminate air, soil and water $(66.35 \%)$, and cause death to humans $(62.05 \%)$. It was also evident from lower Simpson's index of species diversity for sprayed clumps (0.20) and higher for unsprayed (0.32) in cordomom (Aravind, et al., 2018). The present findings are also in line with the earlier observation made by Kumaresan, (1987) who reported as many as 36 natural enemies on cardamom pests on cardamom capsule borer itself under low pesticide usage treatments. Thus, the real threat on the natural enemies in conventional ecosystem should be probed and such chemical components should be eliminated so as to have a balanced ecosystem with scope for optimum natural control.

\section{References}

Aebischer, N. J., 1991, Twenty years of monitoring invertebrates and weeds in cereal fields in Sussex. In: The Ecology of Temperate Cereal Fields (Eds.) Firbank, L.G., Carter, N., Darbyshire, J.F. \& Potts, G.R.). Blackwell Scientific Publications, Oxford, UK, pp. 305-331.

Altieri, M. A., 1995, Agroecology: the science of sustainable agriculture.
Boulder:Westview Process.

Aravind, J., Samiayyan, K. and Kuttalam, S., 2018. Assessing the impact of diafenthiuron 50wp on the pest, pollinator and natural enemy diversity in cardamom ecosystem. Journal of Entomology and Zoology Studies, 6(3): 398-402

Berry, N. A., Wratten, S. D., McErlich. A. and Frampton, C., 1996, Abundance and diversity of beneficial arthropods in conventional and organic carrot crops in New Zealand. New Zealand. J. Crop Hort. Sci., 24(4): 307-313.

Croft, B. A. and Brown, A. W. A., 1975, Response of arthropod natural enemies to insecticides. Ann. Rev. Entomol., 20: 285-335.

Dey, D., 2016, Impact of indiscriminate use of insecticide on environmental pollution. Intern. J. Pl. Prot., 9(11): 264-267.

Firas, 2014, Indiscriminate use and improper application of pesticides by Jordanian vegetable and fruit farmers. Bull. Fac. Agric., Cairo Univ., 65: 344-359.

Kumaresan D, Varadarasan S Gopakumar B. 1987, Review and current status of research on insect pest control in cardamom cropping system. J. Coffee Research, 17:84-87.

Sivasubramaniam, W. and Wratten, S. D., 1995, Effects of insecticides on the abundance of arthropod predators in carrots in Canterbury, New Zealand. Proceedings of the $48^{\text {th }}$ New Zealand Plant Protection Conference, 48: 302-307.

\section{How to cite this article:}

Thirupam Reddy, B. and Giraddi, R.S. 2019. Diversity of Pest, Beneficial Arthropods and Other Non-Target Biota as Influenced by Degree of Pesticide Usage such as Indiscriminate, High, Moderate and Low Use Situations. Int.J.Curr.Microbiol.App.Sci. 8(09): 374-378. doi: https://doi.org/10.20546/ijcmas.2019.809.045 